\title{
CONTRIBUTIONS TO THE PROBLEMS OF GENERALIZATION IN THE PHONOLOGICAL INTERVENTION: A CLINICAL APPROACH
}

\author{
Contribuições para os problemas de generalização em \\ intervenção fonológica: uma abordagem clinica
}

\author{
Víctor M. Acosta Rodríguez ${ }^{(1)}$, Sergio Léon León ${ }^{(2)}$
}

\begin{abstract}
Purpose: to describe the procedure which could be useful for teachers and speech therapists engaged within a school context, in the treatment of the phonological mistakes exhibited by children during their primary-school education. It is an attempt to present an intra-subject study and to observe the generalization suffered by the untrained phonemes and processes during the training of a phoneme. Methods: two children with phonological impairment participated in this research. A Test of Phonology Acosta et al. (1998) was used for the analysis of the simplifications and, later on, an intervention program by minimal pairs was applied. Results: the results seem to indicate that the treatment should start with the process affecting more phonemes and that the most difficult; for example, the phoneme where the process is compulsory applied, should be chosen as the one to be trained. Conclusion: the results showed that treatment must begin with the process that affects a major number of phonemes which have more difficulty in their production.
\end{abstract}

KEYWORDS: Language Development; Speech; Evaluation; Schools

\section{INTRODUCTION}

The understanding of children's articulation mistakes was deeply transformed with the emergence of the phonological approach. The articulator's lack of control or the limitations in the discrimination of hearing were, according to the traditional perspective, responsible for the mistakes committed by the children. The introduction of the phonological components meant that the mistakes started to be considered either as problems in the application of the rules or as processes which simplify the child's speech. The thought behind this new approach was to demonstrate that the treatment of one of those processes will affect multiple phonemes, therefore the training of one or several phonemes ruled by the same process will be extended to others phonemes affected by the same process ${ }^{1}$. However this concept of generalization has caused some problems. Some researchers think that the process of generalization could be ruled by the knowledge that every child has of the phonemes which

(1) Doctor en Ciencias de la Educación. Catedrático de Educación Especial y Logopedia; Departamento de Didáctica e Investigación Educativa; Facultad de Psicología; Facultad de Educación. Islas Canarias. España; Vicepresidente 1ำ de la Asociación Española de Logopedia, Foniatría y Audiología.

(2)

Doctor en Ciencias de la Educación. Ha sido profesor asociado en el Departamento de Didáctica e Investigación Educativa. Facultad de Educación. Universidad de La Laguna. Islas Canarias. España. constitute his mother tongue, knowledge that certainly will allow us to consider the phoneme which could be used to generalize the learning ${ }^{2,3}$. According to some authors, the child could improve his innate system and make some progress (in the processes) if there is a restriction of the processes applied to a sound or to a type of sound ${ }^{4}$. These restrictions could affect the number of sounds used to apply the rules and also the context where they are applied. Furthermore, these restrictions, in the processes, could be optional or compulsory ${ }^{5}$; the latter will always appear if the rules are orderly applied to the context, on the other hand, the optional will appear if the rules are inconsistently applied.

Although it is normally accepted that the acquisition of sounds follow an established order, in reality there is a great amount of variability amongst the subjects concerning both the amount of mistaken phonemes and the type of specific phonemes which are frequently incorrectly produced. This is the reason why the researchers who work in the area of clinical phonology have started to question the usefulness of the procedures of standardized assessment, instead they have raised the need to investigate every child, individually and in depth; testing, at the same time all the hypothesis suggested by the researchers.

There are several descriptive studies based on the notion of phonological processes ${ }^{6-10}$. However it seems that nobody has applied this approach to the treatment of children with a disorderly system. Ramos has done the 
only attempt, her work includes the assessment of phonological processes and also the technique of minimal pairs for the treatment of children with delayed speech ${ }^{8}$. She reports that, after the treatment, the children showed an improvement in three out of the seven processes which were included in the therapy. Nevertheless in her study she assessed and intervened (not only the phonological but also the pragmatic, morphosyntactic and semantic constituents ${ }^{11}$. In this study we attempt to analyze in depth the phonological processes and also to observe how the restrictions in the processes can influence the effects of generalization to phonemes which were not treated during the intervention.

Other objective of this study is to provide a method which will help speech therapists, parents and teachers to cooperate in the re-education of children affected by phonological disorders. This cooperation is urgently needed because:

$\left.1^{\circ}\right)$ The speech therapists are unable to treat all the cases brought to them; they are in charge of too many Centres and too many children.

$\left.2^{\circ}\right)$ As a consequence the speech therapist only sees the children under treatment occasionally (one or twice every week) and only during a very short period of time (half an hour sessions approximately). As a result of this irregularity and also due to the lack of cooperation with the teachers, the children's treatment last several years and their progress not only in the short but in the medium term is sceptically viewed by the teacher.

In the design of this programme of intervention, it has also been carefully contemplated the function of parents and teachers as collaborators on the speech therapist's work although for methodological reasons (we have only one teacher and two children) this question has not been the basic aim of the investigation.

We have tried to answer the following questions:

$\left.1^{\circ}\right)$ Does the training of a phoneme generalize to other phonemes which share the same process?

$\left.2^{\circ}\right)$ Will the training of a phoneme in initial position determine the generalization of the learning to a phoneme inside the word?

$3^{\circ}$ ) How would the generalization be affected at the start of a phoneme training if the rule governing the phoneme is compulsory or optional? When would it be more productive?

$\left.3^{\circ}\right)$ How would the generalization be affected at the start of a phoneme training in the rule governing the phoneme is compulsory or optional? When would it be more productive?

$\left.4^{\circ}\right)$ Could the learning of a second phoneme reduced the advantages achieved by an already trained phoneme or will the advantages remain stables?

\section{METHODS}

Two subjects took part in the investigation. To be selected the children had to show a margin of error of
$40 \%$ or above in two or more phonemes with the exception of the vibrant liquids. The Raven-Color and Busto ${ }^{12}$ tests of exploration of oral motricity were used to examine the children. None of them showed any intellectual, organic or neurological problem.

When the investigation started the ages were five years and 1 month for subject $\mathbf{A}$ and four years and eight months for subject $\mathbf{B}$. Both attended a State School in Tacoronte (Tenerife) and both were in the same class-group.

\section{Design}

To specifically measure the phonemes and the processes exhibited by the children within a frequency of more than $40 \%$, it was decided to design an evaluation test for every child. It was also decided to use a procedure of denomination of pictures to elicit the words included in the individual's evaluation test. The plan was to ensure that the affected phonemes were followed by phonemes from all the articulation points and also from the production moods. All the phonemes, either in initial position or inside the syllable, were evaluated and the percentage of correct answers for both: every position and every phoneme was calculated. Furthermore the processes exhibited by the child were identified. The study was centred on the processes of fronting, backing and dental and velar assimilation, because they seemed to be the only ones affecting to more than one phoneme; the use of this procedure allowed us to measure the generalization to untrained phonemes.

An experimental design of a unique case was used, it combined a multiple survey (or technique of grading probation test) with a line of multiple base (Barlow and Hersen $)^{13}$. The design of a survey with multiple base, as it is called by Gierut, Elbert and Dinnsen ${ }^{2}$, allowed us to group the generalization or transfer which a phoneme under treatment will transmit to another untrained phoneme, moreover the use of this technique gave us the possibility of obtaining two measures: one of them was the real base line. This base line provided a weekly measure on the effects which such a treatment could have on words, containing the treated phoneme, which had not been used in its treatment and also on the position of words others than the trained ones. The technique of grading or multiple surveys was the second line. This line allowed us to measure the generalization to the untreated phonemes. When the students achieved the treatment pre-establish criterion all the phonemes were evaluated again to check if there had been a generalization from trained to untrained phonemes.

This procedure is very practical, it examines the evolution of the answers which can not be independently given and it also eliminates the demand of unnecessary and time-consuming continuous assessment, furthermore the continuous exposure to 
the items on the grading test could produce a spontaneous acquisition of answers (reactive effects). Finally, it also assesses the help provided by the treatment: the training of a phoneme could be eliminated if the phoneme shows progress as a result of the generalization of learning from a trained phoneme.

To resume: the design included the following stages:

1) Individual assessment for every child of the phonemes intended for treatment and the ones outside the treatment (pre-test).

2) Twice a week assessment, on Tuesday and Thursday, of the treated phoneme considering both: the initial and the inside position in the word.

3) Technique of grading (or multiple surveys). To observe the effects of generalization from the trained to the untrained phonemes the initial assessment was reappraised (post-test).

\section{Children training programme}

The procedure used was minimal pairs. Three pairs of words which the subject produced as homonymous were designed for every child. Every subject was given between four and eight words for training. Every Tuesday and Thursday the subjects had to attend training sessions with the speech therapist outside the classroom. Each session lasted about 10 or 15 minutes and it was divided in six phases.

1st. Discriminatory work using minimal pairs. The names of the pictures on the cards were introduced to the child by the speech therapist in the first session. Once the child knew the names of the pictures, he was presented with a pair and was asked to discriminate between each member of the pair. The procedure was as follows: The evaluator placed two pairs on the table and asked the child to identify one of them. At first, only one pair was used but later on the six cards were introduced.

2nd. Production work. The child had to repeat three times consecutively the names of every pair. The evaluator simply asked the name of the picture on the card. If a specific pair presented a problem to the child, it was replaced by a different one, leaving the problematic pair either for the end of that session or for a new one. If a child showed a special problem with relation to a phoneme, i.e., (if in two consecutive sessions he was unable to properly emit the phoneme or he only used it in a few words), the evaluator could use a different placing. For example, a child replacing /k/ by /p/ the evaluator would tell: "There are sounds which are pronounced with the front of your mouth as $/ \mathrm{pa} /, / \mathrm{ba} /$; and others are pronounced with the back of your mouth as $/ \mathrm{ka} /$, /ga/. You always pronounce pasa using the front of your mouth, and I want you to pronounce it using the back of your mouth as /ka/, / $\mathrm{ka} /, / \mathrm{ka} / . . . . . . c a s a "$ The words in bold should be emphasized by the evaluator. This emphasis should allow the child to make a fast correction of his mistakes.

3nd. Presentation of the training words. The child was introduced to five or eight chosen training words and asked to pronounce them. After the therapist showed a card to the child, he would ask him to repeat the name on it. Later the child will be asked to produce its name spontaneously. For those words where the phoneme was difficult to produce the speech therapist used phonetic placement and shaping techniques.

4th. The teacher worked daily in class, during a few minutes, all the minimal pairs and cards learned by the child in one session.

5th. The parents were also given the learned pairs and cards to make the child practice them at home, daily, during a few minutes.

6 th. The training ended when the child committed only one mistake in the spontaneous naming of the cards forming the minimal pairs and in the training words. Immediately after that, and to measure the generalization to untrained words and phonemes in both positions: initial and within the syllable, the individual assessment started.

A positive incentive was used to keep the child interested and motivated with the task. During the training session the child was orally praised every time he produced a correct word. Also at the end of every session he was rewarded not only with sweets or toys but also with a positive verbal reinforcement. Every session ended with a card correctly produced by the child.

When the work took place in the classroom the teacher gave a sweet or a toy to the child if he was able to name, at least, twice consecutively the members of every pair and the training cards of the day.

\section{Programme for teaching training}

A strong collaboration between the teacher and the speech therapist aimed to consider the phonological disorders recuperation programmes was established as an objective from the beginning; to this end we draw what we believe it is a realistic but also a simple programme containing five steps. These five steps were the result of the resolutions to problematic situations raised by the teachers and also the result of the experience which us, together with teachers and students, obtained from some research in the field of language delay. The five steps are the followings:

1st. The first objective was to ensure that the teacher knew every child's specific problem. To achieve this the therapist had to identify exactly the phonemes incorrectly produced by the child and the process or processes which could govern their 
production then, he had to explain to the teacher the nature of the child's problems, consequently the teacher had a very clear objective for his intervention. To clarify the method, the child had to repeat, by imitation, a few words where the processes were compulsory applied. Previously the therapist had predicted the child's answer and then the teacher only confirmed this prediction when she asked the child to imitate two or three words. At the end, the teacher knew the phoneme which should be treated, the processes governing it and the expected results. In this way the teacher obtained a clear idea of the mistaken phonemes in the child's speech and also which phoneme was to be treated.

2nd. To prepare the teacher (the same for the two children) to work with minimal pairs and training words, the therapist developed a short session working only with one or two pairs and one or two training words. Once the teacher learned as the session should be developed, the therapist asked her to repeat it just to ensure her understanding of the procedure.

3nd. The teacher advised the parents about the work they should practice at home with their child. The child has to the told twice the name of the pictures on the training cards which he had already learned in the classroom.

4th. The individual test began when the training of a phoneme was finished. The teacher was, then, introduced to the changes occurred in the child's phonological system. This assessment was used to decide the phoneme to be treated next.

5 th. For the treatment of the second phoneme the therapist assigned more responsibility to the teacher. She was made responsible for the intervention, the therapist visited the Centre only once a week to evaluate the students and help with the doubts the teacher was rising.

\section{Individual treatment}

Every child was trained in two different phonemes following the basic phases of training as stated above:

The treatment for child $\mathbf{A}$ tried to correct the fronting process, using the training of the phoneme $/ \mathrm{k} /$ in initial position. The phoneme $/ \mathrm{g} /$, governed by the same process, was used as phoneme control. This child mistakes could be resumed as follows:

a) She showed a fronting process which converted the phoneme $/ \mathrm{k} /$ in $/ \mathrm{t} /$ or $/ \mathrm{p} /$ optionally in initial or inside position in the word.

b) The phoneme $/ \mathrm{g} /$ was also fronted, converting it into /d/ or /b/ compulsory in an initial position in the word and optionally in an inside position.

The first treatment for child $\mathbf{A}$ lasted two weeks and it consisted of three minimal pairs as they appeared in the following words: corre-torre

cose-tose

carta-tarta

The following five training words were used: kilo, cama, cafetera, escoba and cocodrilo.

The second treatment for $\mathbf{A}$ lasted three weeks and it consisted of three minimal pairs:

$$
\begin{aligned}
& \text { lago-dado } \\
& \text { guía-día } \\
& \text { goma-doma }
\end{aligned}
$$

For this treatment eight training words were used: jugar, ganar, gorila, guisante, gaviota, gasolinera, pingüino and globo.

The phoneme $/ \mathrm{k} /$ was chosen for the first treatment because it was optionally applied in the process; therefore the child could treat the process in this phoneme more easily than in $/ \mathrm{g} /$ where three process was compulsory applied.

Subject $\mathbf{B}$ posed a very difficult case because he exhibited more simplifications processes and more mistaken phonemes than subject $\mathbf{A}$. The phonemes and the processes were the following ones:

a) The phoneme /p/ presented two processes: a dental-alveolar assimilation which converted the $/ p /$ into / $t$ / if the former was followed by a dental-alveolar phoneme, and a velar assimilation which converted/ $\mathrm{p} /$ into $/ \mathrm{k} /$ if the $/ \mathrm{p} /$ was followed by a velar phoneme. These rules were compulsory applied both in initial and inside position.

b) The phoneme $/ \mathrm{m} /$ showed a compulsory process of backing converting it into $/ \mathrm{n} /$ in an initial position. The same process was optional in an inside position.

c) The phoneme /f/ also showed an optional process of backing which converted it into /s/ or /z/ both in initial and inside position.

d) The phoneme $/ \mathrm{b} /$ seemed to be affected by a process of backing which was optionally applied. It meant a change from /b/ into /d/ in an initial position. At the same time, both in initial and inside position, it also suffered an optional process of nasalization applied after the backing process which converted the $/ \mathrm{b} /$ into $/ \mathrm{n} /$. This aspect will be discussed later.

e) The phoneme $/ \mathrm{g} /$ showed a process of labial assimilation optionally applied. It also seemed to be affected by other processes such as nasalization and lost of voicing, however they do not appear to be very consistent.

f) Furthermore there is another compulsory process of palatalization applied to all the consonants preceding the growing diphthongs formed with the palatal vowel /i/.

g) Finally, cases of omission of initial consonants appeared in almost all the phonemes. To shorten this 
section we are not listing all the affected phonemes.

This child received training in two different processes both affecting the same phoneme. The first lasted three weeks and during it the process of dental-alveolar assimilation in the phoneme /p/ was treated. This phoneme was chosen because it seems to be the more difficult for the child. It was affected by two processes: dental-alveolar and velar assimilation. The objective of the first treatment was the dental-alveolar assimilation.

Three minimal pairs were chosen for the first treatment:

$$
\begin{aligned}
& \text { pasa-taza } \\
& \text { pozo-tozo } \\
& \text { pito-tito }
\end{aligned}
$$

During the training the words used were: jugar, ganar, gorila, guisante, gaviota, gasolinera, pingüino and globo.

As already mentioned, the same phoneme but a different process, the velar assimilation, was used in the second treatment. The following minimal pairs were used:

$$
\begin{aligned}
& \text { pico-quico } \\
& \text { poco-coco } \\
& \text { puro-curo }
\end{aligned}
$$

The training words were eight: pescar, pañuelo, pequeño, pico, pistola, payaso, pirata and pizarra.

The results of this investigation can be published with the authority of the Gobierno de Canarias through the Research Project Cl102740601.

\section{RESULTS}

\section{Subject A Analysis}

As already stated this girl exhibited a fronting process converting the velars $/ \mathrm{k} /$ and $/ \mathrm{g} /$ in the dentals /t/ and /d/ respectively. It seemed that only one feature connected with the articulatory point was affected by these substitutions. While some words as queso, castaña, caldero, cuna, raqueta... were incorrectly emitted, others as casa, cubo, conejo, escalera... were always correctly produced in the phoneme target. The phoneme $/ \mathrm{g} /$ seemed to be affected by the same fronting process which converted a $/ \mathrm{g} /$ in a $/ \mathrm{d} /$; this process was compulsory applied in an initial position (there is not a correct word when it begins with $/ \mathrm{g} /$ ) on the other hand, it was optionally applied in a final position as the words águila and yogúr have shown.

The emission of gafas as [báfah] could be interpreted by the reader as a process of labial assimilation, however the existence in the sample of words as café [kafé], cubo [kúbo], pegamento [pegaménto] wich appear in the context where the rule could be applied, seems to contradict the hypothesis.

As already explained, the treatment started with an intervention on the phoneme $/ \mathrm{k} /$, optionally emitted in initial and inside position. During the discriminatory task, the six cards were identified by the girl in two consecutive attempts and without fail; consequently it was presumed that she did not present any discriminatory problem. The development of the treatment can be seen in figures 1 and 2. In these figures, numbers 1 and 2 represent the weekly assessment performed during the training of $/ \mathrm{k} /$. Number 3 expresses the measurement of all the phonemes when the training of $/ \mathrm{k} /$ ended. Number 4 coincides with the end of $/ \mathrm{g} /$ training.

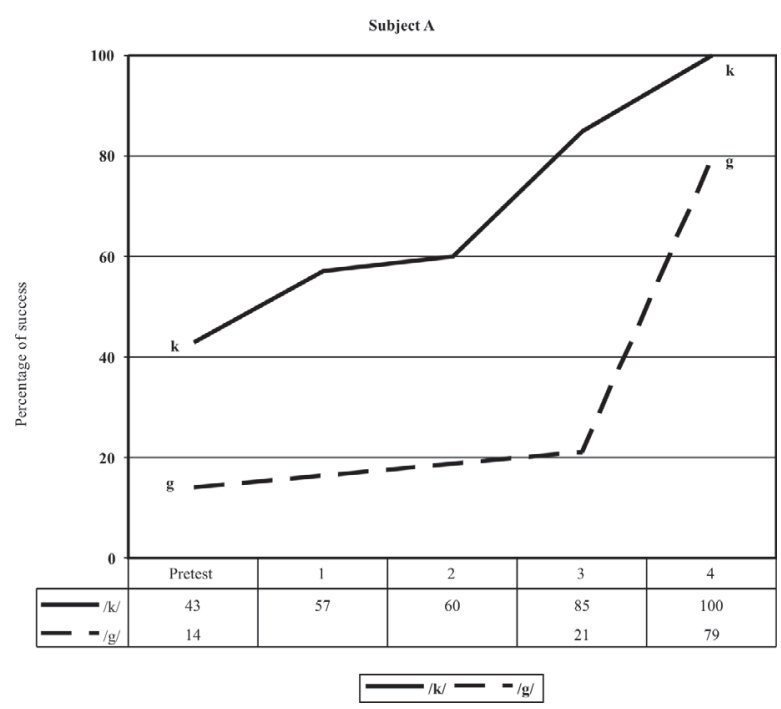

Figure 1 - Evolution of the phonemes $/ \mathrm{k} /$ and $/ \mathrm{g} /$ in the different phases of the study

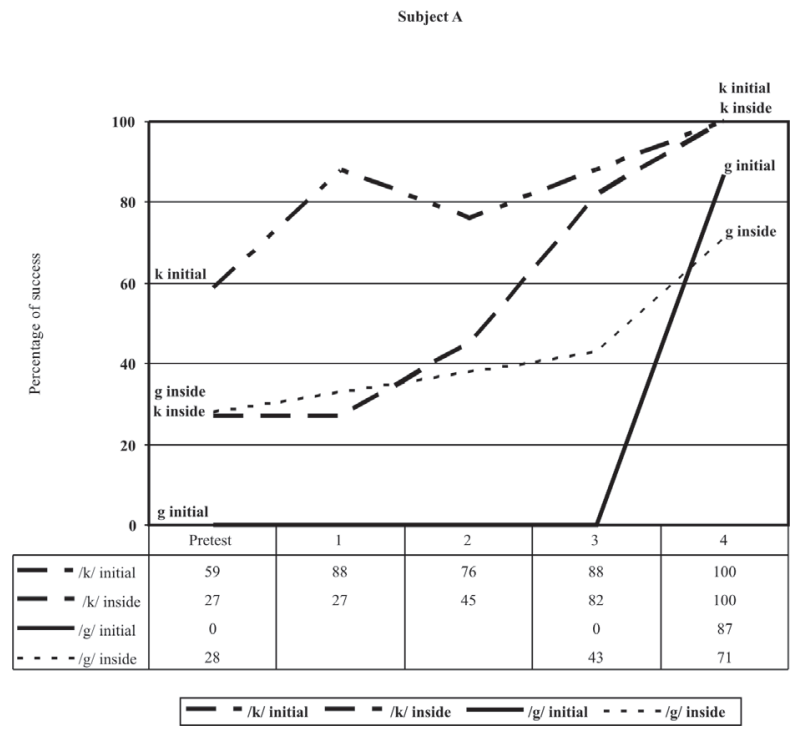

Figure 2 - Evolution of the phonemes /k/ and /g/ depending on the initial or inside position in the word through the different phases of the study 
As we can observe in the figure 1, the training of / $\mathrm{k} /$ allowed this phoneme to reach levels of correction of more than $80 \%$ in only two weeks. However the training of this phoneme did not produce a generalization to the phoneme $/ \mathrm{g} /$ which was affected by the same process.

It can be observed, in the figure 2, that the phoneme $/ \mathrm{k} /$, in initial position, had suffered a strong increase in the number of correct emissions between the pretest and the first week of training. In an inside position, and for the same period of time, /k/ kept the levels showed in the pre-test. Presumably this dissimilarity between the positions is produced because, during the first phases of therapy, the child is totally concentrated in the position used for the trained words. The tendency is reversed in the period between the first and the second training: the inside position will sustain an increase in the number of correct emissions and vice versa, the initial position will suffer a decrease in the correct answers. At the end of the treatment $/ \mathrm{k} /$ , not only in initial but also in inside position, has reached a percentage of more than $80 \%$ correct emissions.

It can also be observed that the generalization to the phoneme $/ \mathrm{g} /$, in initial position, will not advance until the third assessment session, exactly when the training of the phoneme starts. In inside position /g/ showed a small but continuous increase during the training of the phoneme $/ \mathrm{k} /$. This increase was converted in a gain of about 20 points between the pre-test and the final assessment of the phoneme $/ \mathrm{k} /$ (assessment session number 3 ).

In short the analysed data allow us the following conclusion.

First: during the training, the generalization affects phonemes or position of phonemes governed by optional rules, as the training of $/ \mathrm{k} /$ in initial position had shown. It affected not only the same phoneme in an inside position but also to $/ \mathrm{g} /$ in an inside positions too.

Second: the phonemes where compulsory rules are applied do not improve unless they receive a direct training, we can observe this rule during the training of $/ \mathrm{k} /$, the phoneme $/ \mathrm{g} /$ in initial position did not show any progress.

Thirdly: the biggest gains during the treatment (independently of the fact that the rules applied to the phoneme are either optional or compulsory) appear in the phonemes directly trained as the training of the phoneme $/ \mathrm{p} /$ has shown: the percentage of correct answers of $/ p /$, either in initial or in inside position is bigger than those of the untrained phoneme $/ \mathrm{g} /$.

Fourthly: the gains obtained by a phoneme either are kept or could also be increased even if a different phoneme is trained. The gains of $/ \mathrm{k} /$ increased to reach $100 \%$ of correct answers when $/ \mathrm{g} /$ was being trained (assessment session from 3 to 4 ).

\section{Subject B Analysis}

The phonological system of subject B was characterized by a system where all the labial phonemes seemed to be affected by a particular process; the velar phoneme /g/ also seemed to be affected.

The processes presented by this child could be resumed as follows:

a) The phoneme / $/ \mathrm{p} /$ seemed to be affected by two processes of regressive assimilation. The first was a dental-alveolar assimilation which converted the /p/ into /t/ when the former was followed by a dentalalveolar or palatal phoneme. Nevertheless these rules did not seem to apply to all the words. For example, the word pájaro, produced by the child as [táharo] could have been produced as [kájaro] since it was followed by the velar $/ x /$. The problem can be solved, however, if we accept that it was the $/ r /$, in the last syllable, the segment used for its assimilation. The word paraguas shows a similar problem: the $/ p /$ should have been $/ t /$ because the element following the $/ p /$ is an alveolar sound $/ \mathrm{r} /$; this problem can also be solved accepting that it was $/ \mathrm{g} /$ the consonant in the last syllable the one used for assimilation. A different problem appears with words as patines, emited as [katíneh] by the child although all the elements following the $/ \mathrm{p}$ / are dental-alveolar; the only possible explanation was the application of a dissimilation rule to avoid that the three consonant segments in implosive position (onset of the syllabe), became dental-alveolar and produced a word like [tatíneh]; the verisimilitude of this rule increases if we consider the similarity of pelota [kelóta]. Obviously all these ideas are only possibilities which should be proven by a test examining every one of the suggested hypothesis. Although these hypotheses were not at the core of the investigation we have discussed them because they seem realistic to us and also because they help the initial hypothesis based on only two important and general processes.

b) The phoneme $/ \mathrm{m} /$ seemed to be affected by a process of backing which compulsory converted it in $/ \mathrm{n} /$ in initial position of word and optionally in inside position. There also was a process of omission of elements in initial position of word (montaña [entaña], mariposa [tosa]). This process will be further explained when the phoneme /b/ will be analyzed.

c) The phoneme /f/ seemed also to be affected by a backing process, optionally applied, and which converted it in $/ \mathrm{s} /$ or $/ \mathrm{z} /$. It is interesting to observe that in the word cafetera, /f/ became /h/. An easy explanation could be the following: if it had been replaced by an /s/it would have had three consecutives phonemes in the same zone of articulation /s/, /t/, /r/ , which would have produced [kasetéra]. As already explained in the case of $/ p /$, this situation seems not 
to be accepted by the child system, consequently, to get a dissimilation it had to be converted in $/ x /$.

d) The phoneme $/ \mathrm{b} /$ presented the highest variability. It can be said that it suffered a process of backing which converted it in $/ \mathrm{d} /, / \mathrm{n} /$ or $/ \mathrm{g} /$ and also another process where it was usually eliminated in initial position of word. It can also be said, looking at the process of backing that the normal occurrence was to be replaced by /d/, however it was frequently replaced by $/ \mathrm{n} /$; this change, therefore, implied the application of two processes: backing and nasalization; however it does not seem that the last process could be accepted as an assimilation because although nasalization is possible in the word baño [náo] where it is followed by a velar segment, it is not possible in words as caballo [kanáyo] or nevera [nenera]. In the last case we could accept a progressive assimilation but in the case of caballo the process will remain unexplained. Furthermore if we accept a progressive assimilation for caballo it should also be accepted for baño. As the available information does not provide a plausible explanation for these changes they have been categorised (defined) as feebles. A different case is the change of $/ \mathrm{b} /$ into $/ \mathrm{g} /$ because these phonemes, in spite of having two different points of articulation, are acoustically very similar, mainly if they are followed by the high velar vowel /u/. Words like abuelo, bueno, etc., are frequently articulated which $/ \mathrm{g} /$ due to the great similarity shown by the two consonants in this control. Lastly, omission, in initial position is another process which could affect the phoneme /b/. May be these omissions could partly be explained by the presence, in a word, of a syllable with the structure CVC, where the rhyme consonant is always nasal; this theory was based observing that words like buzón, bufanda and ventana, always fulfil this requirement. Furthermore the same situation appears in the word montaña where the first consonant (also labial) is omitted. These facts confirm the idea that the phoneme position within the word and the syllabic structure are two variables which could be used to explain many children's mistakes ${ }^{8}$

e) $/ \mathrm{g} /$ is the last phoneme to be analysed, it does not seem to be affected inside the word by any simplification process however it is affected in an initial position. From our perspective, it is clear that due to a process of assimilation of labial /g/ changes into /b/ when it is followed by a labial consonant, however this conclusion based on only two examples is open to discussion. The changes of $/ \mathrm{g} /$ into $/ \mathrm{k} /$ and $/ \mathrm{n} /$ cannot be explained with the data at our disposal. In any case it can be concluded that the rules seem to be optionally applied in the phoneme $/ \mathrm{g} /$.

f) The last rule in this inventory is a phonotactic rule which palatalizes the phoneme preceding the high palatal semi consonant /j/, for example in the words columpio, piano, serpiente, rompió, comiendo, avión, labios and bebiendo. This phonotactic restriction is compulsory.

The first treatment applied to this child attempted to eliminate the dental-alveolar assimilation which was produced in the phoneme/p/. This process was chosen because it was compulsory applied and it could also be useful to study all the labial phonemes affected by backing. The first treatment lasted over three weeks. In the second training session we had to resort to phonetic placement and shaping techniques because the child was incapable of emitting any word containing $/ p /$ in spite of the fact that he was capable of discriminating them. The objective of the second treatment was the process of velar assimilation, affecting also the phoneme $/ \mathrm{p} /$. This treatment took another three weeks.

The percentage of correct answers for each phoneme appears in the figure number 3 . The numbers 1,2,3,4 represent the assessment implemented (set twice a week). The number 5 expresses the assessment of the first treated process. The number 6 is the assessment of the second treated process.

As it can be seen in the figure number 3 , the phonemes which seem to have experienced a substantial increase in the percentage of correct answers during the application of the process of dental-alveolar assimilation were the treated phoneme / $\mathrm{p} /$ and the phonemes $/ \mathrm{m} /$ and $/ \mathrm{b} /$. The phonemes $/ \mathrm{f} /$ and $/ \mathrm{g} /$ experienced only a small increase in the percentage of correct answers. However it has to be added that it was only in the second assessment when the treated phoneme $/ \mathrm{p} /$ started to show the first positive answers. Furthermore, all the correct answer were practically related to the trained process and not to the words governed by the process of velar assimilation. When the first treatment ended (dentalalveolar assimilation) there were only two words correctly emitted where $/ \mathrm{p} /$ had been replaced by $/ \mathrm{k} /$ . The first one was puro, a word which could not really be qualified as a velar assimilation because there was not a velar consonant which could assimilate the /p/. Really it seemed more logic that the change in this word would had been from /p/ into / $/$ / because $/ r /$ is an alveolar phoneme. May be this could explain why this word was the fist to show some improvement in the whole inventory. The second word was pocos, the only word where the velar assimilation was clear; its improvement was a consequence of the training in the process of dental-alveolar assimilation. When the second treatment was introduced, the phoneme /f/ experienced an important improvement, on the other hand $/ \mathrm{b} /$ and $/ \mathrm{g} /$ remained practically the same, as they appear after the first treatment.

As a summary it can be concluded that at the end of the investigation the labials were the phonemes which experienced a real improvement as a consequence of the treatment and, on the contrary 


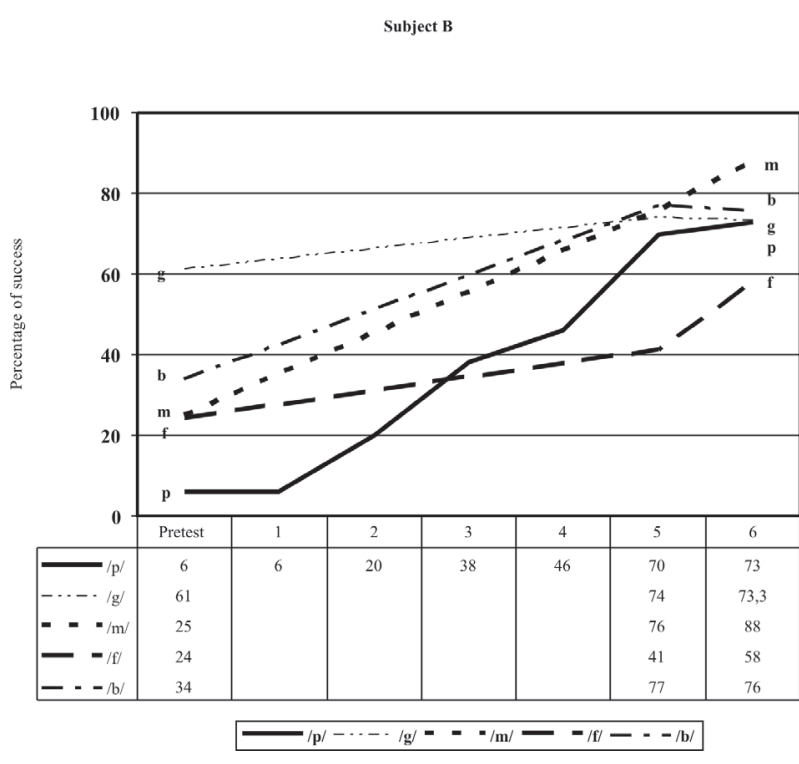

Figure 3 - Evolution of the phonemes /p/, /g/, /m/, /f/ and $/ b /$ in the different phases of the study

the velar phoneme did not show any relevant change in spite of being the phoneme which exhibited the fewer mistakes during the pre-test. Figures 4 and 5 show the evolution, during all the phases of the treatment, of the different phonemes, both in initial and inside position.

As it can be seen in figure 4, all the phonemes in an initial position showed some improvement, especially $/ \mathrm{m} /$ and $/ \mathrm{p} /$ which were the phonemes where the compulsory processes were applied in an initial position. When the training ended the contrast $/ \mathrm{p} / \mathrm{-} / \mathrm{t} /$ were the phonemes showing the highest percentage of correct answers in spite of the fact that during the pre-test the number of correct answers was zero. When the process of velar assimilation in $/ \mathrm{k} /$ was treated, it was again the phonemes $/ \mathrm{p} /$ and $/ \mathrm{m} /$ the ones showing a continuous improvement.

The only phonemes which did not show any improvement during the training in the process of velar assimilation were /f/ and $/ \mathrm{g} /$ in the final position in the word. When the training in the process of velar assimilation started, the number of correct answers in $/ \mathrm{p} /$ and $/ \mathrm{b} /$ decreased but increased in $/ \mathrm{f} /$ which appears to be the only phoneme keeping the same rate of answers as in the pre-test. This case seems to contradict the criterion number 4 formulated for the subject $\mathbf{A}$, which sustained that the gains remain unaltered during another phoneme training. Perhaps the divergence could be explained if we consider the number of mistakes exhibited by each child: the first one had only two and the second one five. May be that when the child is trying to learn a contrast, concentrate himself, in a particular moment in a few phonemes. This explanation is plausible because the child could decrease his rate of correct answers when

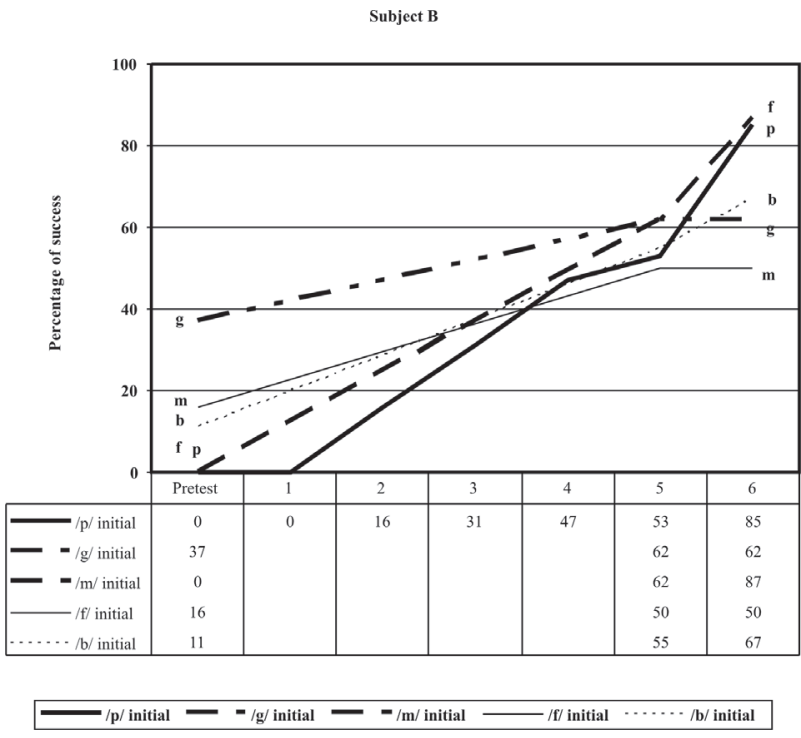

Figure 4 - Evolution of the phonemes $/ \mathrm{p} /, / \mathrm{g} /, / \mathrm{m} /, / \mathrm{f} /$ and $/ b /$ in the initial position, in the different phases of the study

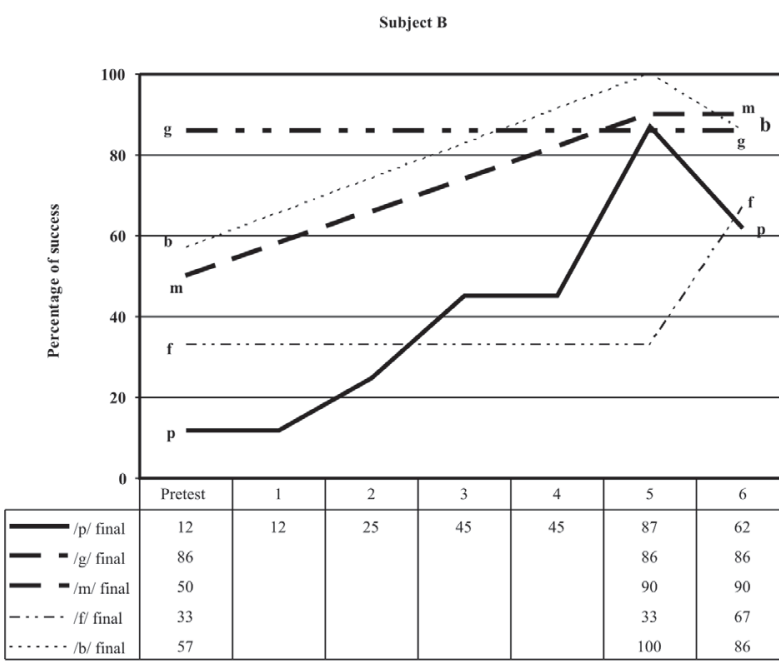

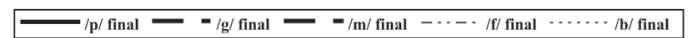

Figure 5 - Evolution of the phonemes $/ \mathrm{p} /, / \mathrm{g} /, / \mathrm{m} /, / \mathrm{f} /$ and $/ b /$ in the final position, in the different phases of the study

he was learning other phonemes which share some characteristics with the phoneme he was learning.

The explanation of the given data is not easy; apparently the phonemes where a compulsory restriction was applied were the ones experiencing a higher increase in correct answers: it looks like a direct contradiction from the results obtained in the first study. It seems a normal occurrence that $/ p /$, the phoneme chosen for the application of the treatment showed and increase in correct answers. This occurrence seems to agree with the conclusion formulated after the training of subject $\mathbf{A}$. However, the case of the phoneme $/ \mathrm{m} /$ cannot be explained by any of the rules used in the previous example, because 
when a compulsory rule is applied to it, it should not show more improvement than other phonemes where a restriction is optionally applied.

A lengthy study of the information would allow the formulation of a hypothesis which could explain the improvement in $/ \mathrm{m} /$. If we look at the remaining control phonemes it can be observed that the phoneme /f/, in an initial position was emitted as /f/, /s/, /z/, /h/; the phoneme $/ \mathrm{b} /$ also in initial position could be either emitted as /b/, /d/, /n/, /g/ or omitted altogether. The phoneme $/ \mathrm{g} /$ was either replaced by $/ \mathrm{b} /, \mathrm{k} / \mathrm{l} / \mathrm{g} /$ or omitted. The phoneme $/ \mathrm{m} /$, however, was always replaced by $/ \mathrm{n} /$ or omitted. Furthermore, the generalization, in this case was done at a fast pace, may be, because $/ \mathrm{m} /$ was always substituted by the same phoneme. If we look at the information on $/ \mathrm{m} /$ it can be observed that: 1st) the process of omission persisted and $2 \mathrm{nd}$ ) all the words where it was substituted by $/ \mathrm{n} /$ showed some improvement. If we compare this data it seems clear that the phonemes which suffer different types of substitution, as $/ \mathrm{b} / \mathrm{or} / \mathrm{f} /$ need to be treated to reduce its variability. Therefore, it seems that what is needed is to find the real subjacent representation of a phoneme and then to eliminate the conflicting phonemes which only add instability to its production.

As a result the previous case could be enriched with the following conclusion: the more consistent or stable the child's productions are the more possibilities that the child will learn to suppress his mistaken phonemes consequently, one of the first objectives of the therapy should be the elimination of any instability.

The last conclusion is the following: when a rule or a group of rules are compulsory applied to a phoneme, they are not positively affected by the training of a different set of rules, they have to be directly treated. If we observed, in the figure number 5 , the behaviour of $/ \mathrm{g} /$ where processes of almost fronting $(/ \mathrm{g} / \rightarrow / \mathrm{b} / ; / \mathrm{g} / \rightarrow / \mathrm{n} /)$ and of lost of voicing $(/ \mathrm{g} / \rightarrow / \mathrm{k} /)$, are applied, the non progress of $/ \mathrm{g} /$ in an initial position could be explained. This occurrence can also be observed in the palatalization process which affects the rising diphthongs with /j/ where words as columpio, piano, serpiente, rompió, peine, avión, labios and bebiendo, continued to be wrongly emitted even after the training of the two treated processes.

\section{DISCUSSION}

The assessment and treatment of children phonologically delayed entitles not only to fulfil an evaluation protocol but to register a process and to treat it, using a phonological procedure such as minimal pairs or the cyclical approach. Many of the principles and concepts applied to the assessment and treatment of the phonological problems have been assumed by researchers and speech therapists without a deep analysis of their causes. One of the most controversial themes is focused in the process of generalization: to find variables which would allow more precise predictions to foresee the generalization produced during the training to processes or phonemes indirectly treated. Within this context this investigation is an attempt to contribute a small speck of sand to the study of the generalization problem.

The results obtained in this investigation can be summarized in four principles:

$\left.1^{\circ}\right)$ during the training of a process the highest gains are obtained by the phonemes directly trained.

$\left.2^{\circ}\right)$ At the beginning a child will probably learn very easily and without a direct training the rules which are optionally applied, on the other hand the rules compulsory applied will have to be directly trained.

$\left.3^{\circ}\right)$ An unstable or inconsistent phoneme production is a handicap for its recuperation, therefore one of the main objectives of the training should be directed to stabilize the phoneme production.

$4^{\circ}$ ) When a process affects a considerable amount of sounds we should not expect either all the phonemes to advance at the same time or to reach the same level because the knowledge which the child has about the different phonemes is usually dissimilar: some phonemes being more accessible to be controlled by the child than others.

Others researchers who have also investigated these principles have arrived to conclusions which present some similarities to the ones introduced in this research. For example Dinnsen and Elbert ${ }^{14}$ in a study very similar to ours had arrived to the conclusion that there were, at least, three general factors which could explain the improvement showed after the treatment; they are: 1st) the productive phonological knowledge: the learning of phonemes where optional rules are applied will be considerably easier than the learning of phonemes where compulsory restrictions are applied; 2nd) the phonemes or processes directly treated will experience more improvements than the ones indirectly treated; $3 n d$ ) there is a problem inherent to each and every type of sound (for example the nasal sounds are easily acquired in comparison with the liquids which are the most difficult sounds to be acquired).

As it can be observed, there is a coincidence between two of the above principles and the two first ones as proposed by us in this investigation. Other researchers as Gierut, Elbert and Dinnsen have also shown that the productive phonological knowledge is a variant which could explain the gains in an specific a treatment ${ }^{2}$.

Ingram ${ }^{15}$ quoting from another authors, do recommend that one of the therapy's objectives should be to eliminate the instability or inconsistency in the child's production, agreeing, in this case, with our third principle.

The fourth principle could be included in the inventory's restrictions. Edwards ${ }^{4}$ and also Ingram ${ }^{15}$ suggest that one of the strategies followed by the 
child to acquire his maternal language's contrast system is to apply some type of restriction in his inventory to facilitate its learning.

The four principles previously formulated should be considered when the assessment and treatment of phonological delayed children are planned, because they could determine the direction the treatment should follow.

We suggest, as a final summary, that the following guidelines should be adopted during the assessment and training of phonological delayed children.

On one hand, relating to assessment we propose four main points, that is to say:

1st) You should use a screening test to conclude which processes are the ones working in the child's phonological system.

2nd) You should prepare some words to evaluate each process and each phoneme. To be able to appreciate the assimilation, it is important that the problematic phonemes are followed by phonemes with a different place and manner of production.

3nd) You should use for the analysis an ample, general pattern and you should not explain each and every one of the changes emitted by the child: the system will always present some inconsistencies.

4th) You should consider the different position of the phonemes within the word and should take note whether the processes and rules present either an optional or a compulsory character.

On the other hand, the suggestions for the phonological training are as follows: 1st) You should start with the process which affects more phonemes. Consider that the processes do usually operate on type of sounds not on isolated sounds. For example, in the case of subject $\mathbf{B}$, as above explained, all the labial sounds were affected; therefore one of them was chosen to start the therapy.

2nd) Within this process you should choose the most difficult phoneme as the one to be trained, there is to say, the phoneme where the process is compulsory applied.

3nd) The phoneme in an initial position should be chosen to start the training: because the training in this position will probably produce a generalization to another position.

4th) You should use a procedure of contrast (minimum or maximum). It seems that the use of this procedure will allow the child to learn more than the mere contrast between two sounds.

5th) If the child is unable to emit the targeted sound you should use either phonetic placement and shaping techniques. Once the child succeeds in pronouncing the sound in two or three words, do immediately repeat the phonological treatment (minimum or maximum pairs).

6th) To end the treatment of a phoneme you should use a very demanding criteria. We suggest a criterion of $80 \%$, or above, correct answers. Once this criterion is reached you should evaluate the generalization to other phonemes/processes and do start again from the first step.

\section{RESUMO}

Objetivo: descrever procedimento de intervenção fonológica. Métodos: duas crianças com transtorno fonológico participaram do estudo. Foi aplicada a prova de Fonologia de Acosta et al. (1998) para o levantamento das simplificações e, posteriormente, aplicado o programa de intervenção por pares mínimos. Resultados: observou-se generalização dos fonemas e processos fonológicos não treinados durante o tratamento. Conclusão: os resultados indicam que o tratamento deve começar por aqueles processos que afetam um maior número de fonemas e que apresentam maior dificuldade em sua produção.

DESCRITORES: Desenvolvimento da Linguagem; Fala; Avaliação; Instituições Acadêmicas

\section{REFERENCES}

1. Fey M. Phonological assessment and treatment: articulation and phonology: inextricable constructs in speech pathology. Hum Commun Canada. 1985; 9:7-16. 2. Gierut J, Elbert M, Dinnsen D. A functional of phonological knowledge and generalization learning in misarticulating children. J Speech Hear Res. 1987; 30: 462-79.
3. Elbert M. Consideration of error types: a response to Fey. Lang Speech Hear Serv School. 1992; 23:2416.

4. Edwards M. Clinical forum: phonological assessment and treatment. Lang Speech Hear Serv Schools. 1992; 23:233-40.

5. Dinnsen D. Methods and empirical issues in analyzing functional misarticulation. ASHA Monographs. 1984;22:5-17. 
6. Bosch L. Identificación de los procesos fonológicos de simplificación en el habla infantil. Rev Logop Foniatr Audiol. 1983; 4:195-200.

7. González M. Trastornos fonológicos: teoría y práctica. Málaga: Servicio de Publicaciones de la Universidad de Málaga; 1989.

8. Ramos V. Evaluación e intervención en el retraso fonológico de escolar canarios en edades de 4 a 6 años: un enfoque multidimensional y comunicativo desde la perspectiva de los procesos fonológicos. [doctoral]. Departamento de Didáctica e Investigación Educativa y del Comportamiento. Universidad de La Laguna. Islas Canarias. 1996.

9. Acosta V. Naturaleza, evaluación e intervención en las dificultades fonológicas desde el enfoque de las reglas fonológicas. Rev Logop Foniatr Audiol. 2000; 2:96-108. 10. Acosta $V$, Ramos V. Procesos fonológicos: evaluación y tratamiento. Rev CEFAC. 2006; 8(1):27-35.

11. Acosta V, Ramos V. Estudio de los desórdenes del habla infantil desde la perspectiva de los procesos fonológicos. Rev Logop Foniatr Audiol. 1998; 18:124-42. 12. Busto M. Manual de logopedia escolar. Madrid: Cepe; 1995.

13. Barlow D, Hersen M. Single case experimental designs. London: Pergamon; 1984.

14. Dinnsen $D$, Elbert M. On the relationship between phonology and learning. ASHA Monographs. 1984; 22:59-68.

15. Ingram D. Phonological disability in children. London: Edwards Arnold; 1976.

RECEBIDO EM: $15 / 11 / 06$

ACEITO EM: 21/02/07

Endereço para correspondência:

C/. Acebiño, nº1 (Urbanización Jardín del Sol)

38350 Tacoronte

Tenerife (Canary Islands). Spain.

Tel.: 922319025/ 922571737

E-mail:vacosta@ull.es 